\title{
Intratympanic Injections: An Unsolved Mystery
}

\author{
Kartik Parelkar, Vandana Thorawade, Mohan Jagade, Smita Nagle, Rajanala Nataraj, \\ Madhavi Pandare, Reshma Hanwate, Bandu Nagrale, Kiran Kulsange, \\ Devkumar Rangaraja, Arpita Singhal \\ Department of ENT, Grant Government Medical College \& Sir J.J. Group of Hospitals, Mumbai, India \\ Email: kartikparelkar@ymail.com
}

Received 18 February 2015; accepted 9 March 2015; published 12 March 2015

Copyright (C) 2015 by authors and Scientific Research Publishing Inc.

This work is licensed under the Creative Commons Attribution International License (CC BY). http://creativecommons.org/licenses/by/4.0/

(c) $\underset{\mathrm{EY}}{\mathrm{ir}}$ Open Access

\begin{abstract}
Aims: The aim of this study was to test the effectiveness of intratympanic dexamethasone injections as a treatment for severe disabling tinnitus and also observe its effect on hearing loss if any. Materials and Methods: Thirty patients with severe disabling tinnitus in the age group 20 to 60 years were selected and randomly assigned to receive intratympanic injections of a dexamethasone solution $4 \mathrm{mg} / \mathrm{ml}(0.5 \mathrm{ml})$ or isotonic saline $(0.5 \mathrm{ml})$ solution under topical anaesthesia, once per week for 4 weeks using a zero degree endoscope. Improvement in tinnitus was assessed using a visual analog scale, considering 2-point improvement as significant and alteration in hearing if any was noted by pure tone audiometery before and after the therapy. Results: The improvement in tinnitus was not significant, with no alteration in audiometery reports. Conclusions: Intratympanic therapy is an attractive mode of treatment because of its highly targeted delivery, low concentration of the drugs required and a very good patient tolerance. Although there has been no breakthrough in intratympanic therapy for tinnitus or other otological conditions, accessibility to the inner ear through the semipermeable round window membrane holds many promises in the near future.
\end{abstract}

\section{Keywords}

Intratympanic Injection, Round Window, Tinnitus, Dexamethasone

\section{Introduction}

One of the principal advantages of intratympanic (IT) therapy is the ability to deliver therapeutic concentrations of the drug in a highly targeted fashion to the inner ear, thus avoiding systemic side effects.

How to cite this paper: Parelkar, K., Thorawade, V., Jagade, M., Nagle, S., Nataraj, R., Pandare, M., Hanwate, R., Nagrale, B., Kulsange, K., Rangaraja, D. and Singhal, A. (2015) Intratympanic Injections: An Unsolved Mystery. International Journal of Otolaryngology and Head \& Neck Surgery, 4, 124-132. http://dx.doi.org/10.4236/ijohns.2015.42022 
Diffusion occurs across the round window membrane (RWM) into the cochlea, driven by the concentration gradient between the middle ear and the perilymph-filled scala tympani. The diffusion rate is determined by various factors, such as size, configuration, concentration, liposolubility and electrical charge of the active substance, as well as by the thickness of the RWM [1].

A cochleostomy for direct drug delivery entails a substantial risk of permanent damage, whereas RWM provides an attractive gateway to the inner ear. It consists of three layers: an outer epithelium facing the middle ear, a core of connective tissue, and an inner-ear epithelium bordering the inner ear [2].

Compared with IT doses, much higher systemic doses are required when action is intended on the inner ear which is an end organ with blood brain barrier [3].

In 1996, Sakata et al. treated 1214 patients who had tinnitus by infusing dexamethasone solution into their middle ear. The authors reported good overall results in $77 \%$ of the ears immediately after the treatment and in $68 \%$ after 6 months [4].

In 2000, Shulman and Goldstein treated 10 patients having tinnitus with intratympanic dexamethasone injections [5]. Five patients experienced tinnitus control for at least 1 year and 2 had tinnitus control for only a few hours. Three patients experienced no improvement.

In 2002, Cesarani et al. described 54 patients treated with intratympanic dexamethasone injections [6]. Of these patients, 34\% experienced complete resolution of tinnitus, $40 \%$ experienced significant improvement, and $26 \%$ experienced no change.

However, it should be noted that placebo effect is very high with tinnitus and having a control group is essential. Hence, we conducted this study and would like to report our experience regarding IT therapy for refractory tinnitus.

\section{Methodology}

Patients having severe disabling tinnitus (SDT) for at least 6 months, refractory to medical line of management in the age group of 20 to 60 years were selected from the ENT out patient department at the Grant Government Medical College and J.J. Group of Hospitals, Mumbai.

Study was conducted from July to December 2014, however it is an ongoing study and we intend to try different molecules for management of refractory tinnitus via the intratympanic route.

Patients with sensorineural, mixed and conductive hearing loss were all included and their pure tone audiogram findings noted prior to the study. Patients with $\mathrm{h} / \mathrm{o}$ trauma to the ear and carcinomas were excluded from the study.

Detailed history taking, otomicroscopic examination and audiologic testing were also performed to identify the presence of otological diseases associated with the symptom of tinnitus apart from the hearing loss.

The patients were given a specific tinnitus questionnaire regarding: tinnitus duration, ear affected, subjective hearing loss, description of the sound heard and known otologic diseases/previous treatments. The patients were then asked to indicate the intensity of tinnitus on a visual analog scale graded from 1 to 10 ( 1 was low and 10 was an unbearable level of intensity). Informed consent was obtained from all patients.

The patients were then randomly assigned to receive $0.5-\mathrm{ml}$ IT injection of either a $4-\mathrm{mg} / \mathrm{ml}$ dexamethasone solution or isotonic saline. They were placed in a supine position with their heads turned about $45^{\circ}$ towards the unaffected ear. Topical anaesthesia of the tympanic membrane was administered using 10 percent lignocaine spray, complete clearance of which was done using suction after 2 to 3 minutes. Using a $2 \mathrm{ml}$ syringe and a 26gauge one and half inch needle, the assigned solution was injected under direct vision using a zero degree endoscope in the postero-inferior quadrant of the tympanic membrane (Figure 1 and Figure 2). Each patient remained for about 30 minutes in the described position. Four injections were performed, 1 per week for 4 weeks.

In case of Meniere's disease grommet insertion was done and IT therapy was given through the grommet.

After finishing the treatment, the patients indicated, on the visual analog scale, the level of tinnitus intensity following the treatment. We considered that improvement was significant when a lowering of at least 2 points on the visual analog scale was reported.

Also patients pure tone audiometery was repeated after completion of the therapy. Five patients who started treatment were excluded from analysis ( 3 from the study group and 2 from the control group) because they did not complete treatment or failed to return for follow-up. Of the 25 patients who remained, 5 had both ears treated. Thus, a total of 30 ears were treated and evaluated. 


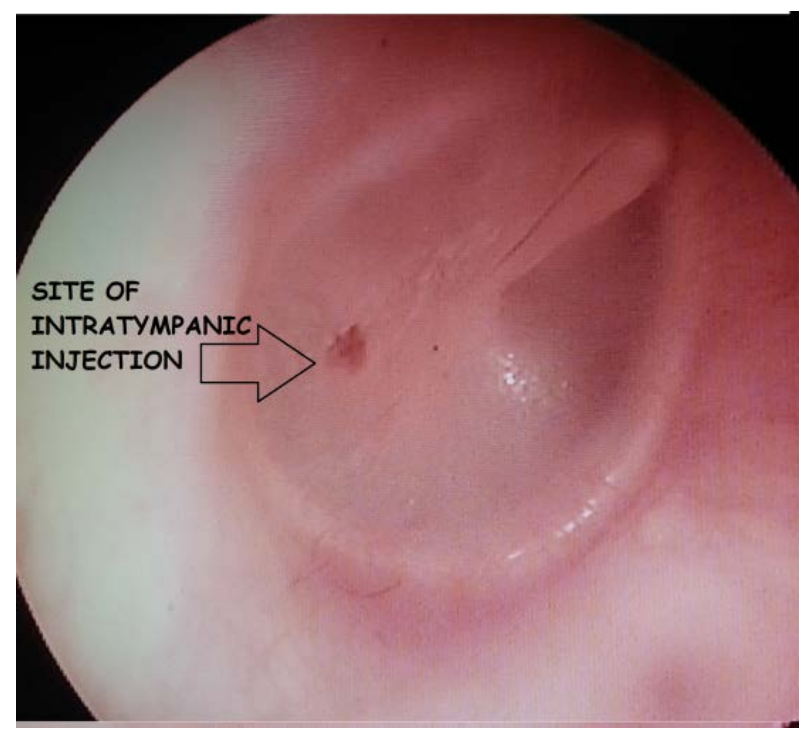

Figure 1. Site of injection showing a blood clot as a result of previous injection.

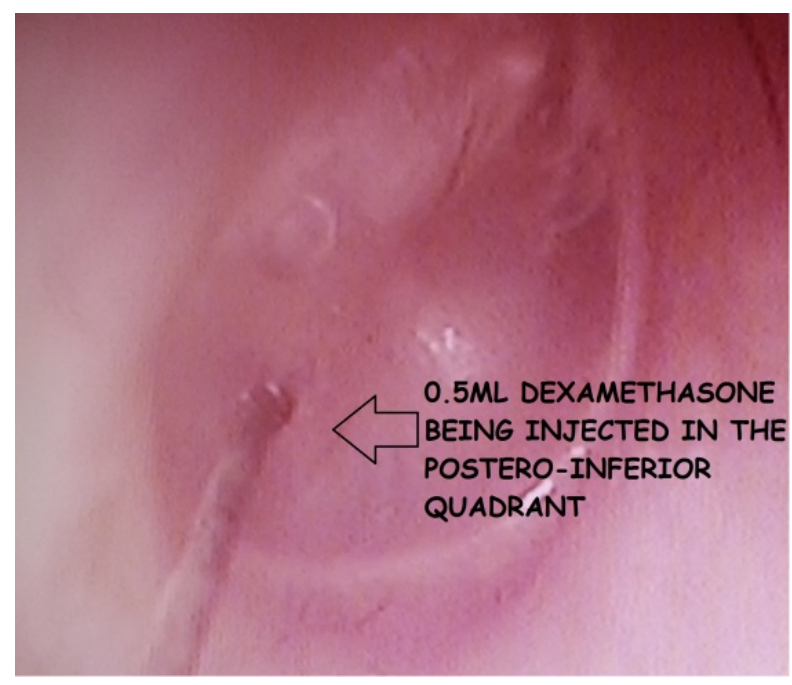

Figure 2. IT injection.

\section{Results}

From the data provided in Tables $1-3 ; \times 2$ test (with a significance level of 0.05 ) showed no significant difference between the groups regarding sex, age and laterality of the tinnitus (Tables 4-6 respectively). There was no significant difference between the results of treatment with a dexamethasone solution and treatment with a saline solution (Table 7). There was no change in the hearing levels before and after treatment as per the pure tone audiogram reports in both the groups.

\section{Discussion}

The fact that intratympanic therapy was first used for tinnitus and not Meniere's has probably been forgotten.

Harold Schuknecht proposed the use of streptomycin in Meniere's disease as an alternative to surgical labyrinthine ablation in 1956 [7]. 5\% ethylmorphine hydrochloride, was used for intratympanic injections in cases of tinnitus by Trowbridge. He treated 20 patients and claimed complete tinnitus relief in 11 of them, partial improvement in seven and no change in the remaining two [8] [9]. 
Table 1. Gives the otologic diagnosis for the 30 ears, with the number and percentage of ears with each diagnosis.

\begin{tabular}{ccc}
\hline Diagnosis & Ears No. & Percentage \% \\
Presbyacusis & 10 & $33 \%$ \\
Idiopathic & 8 & $27 \%$ \\
CSOM & 4 & $13 \%$ \\
Menieres disease & 2 & $7 \%$ \\
Otosclerosis & 2 & $7 \%$ \\
NIHL & 2 & $3 \%$ \\
Ototoxicity & 1 & $3 \%$ \\
\hline
\end{tabular}

CSOM: chronic suppurative otitis media. NIHL: noise induced hearing loss.

Table 2. Gives the otologic diagnoses in the 16 ears of the study group (who received $0.5 \mathrm{ml}$ dexamethasone).

\begin{tabular}{|c|c|c|c|c|c|c|}
\hline \multirow[t]{2}{*}{ Patients No. } & \multirow[t]{2}{*}{ Sex/age } & \multirow[t]{2}{*}{ Side of symptom } & \multicolumn{2}{|c|}{ Visual analog scale score } & \multirow[t]{2}{*}{ Complications } & \multirow[t]{2}{*}{ Diagnosis } \\
\hline & & & Pre-treatment & Post-treatment & & \\
\hline 1 & $\mathrm{M} / 53$ & $\mathrm{R}$ & 8 & 7 & - & Presbyacusis \\
\hline 2 & $\mathrm{M} / 47$ & $\mathrm{~L}$ & 6 & 6 & - & Presbyacusis \\
\hline 3 & $\mathrm{M} / 60$ & $\mathrm{~L}$ & 7 & $5^{*}$ & Vertigo & Presbyacusis \\
\hline 4 & $\mathrm{M} / 60$ & $\mathrm{R}$ & 7 & $5^{*}$ & Vertigo & Presbyacusis \\
\hline 5 & $\mathrm{~F} / 55$ & $\mathrm{~L}$ & 7 & 7 & - & Presbyacusis \\
\hline 6 & $\mathrm{~F} / 55$ & $\mathrm{R}$ & 7 & 7 & - & Presbyacusis \\
\hline 7 & $\mathrm{~F} / 32$ & $\mathrm{R}$ & 6 & 6 & - & Idiopathic \\
\hline 8 & $\mathrm{M} / 22$ & $\mathrm{~L}$ & 8 & 8 & - & Idiopathic \\
\hline 9 & $\mathrm{M} / 27$ & $\mathrm{~L}$ & 6 & 5 & Vertigo & Idiopathic \\
\hline 10 & $\mathrm{M} / 27$ & $\mathrm{R}$ & 6 & 5 & Vertigo & Idiopathic \\
\hline 11 & $\mathrm{M} / 45$ & $\mathrm{~L}$ & 7 & 6 & - & CSOM \\
\hline 12 & M/35 & $\mathrm{R}$ & 7 & 7 & - & CSOM \\
\hline 13 & $\mathrm{M} / 42$ & $\mathrm{~L}$ & 7 & 7 & - & Menieres d. \\
\hline 14 & $\mathrm{M} / 30$ & $\mathrm{R}$ & 6 & 5 & - & NIHL \\
\hline 15 & $\mathrm{~F} / 43$ & $\mathrm{R}$ & 6 & 6 & - & SSNHL \\
\hline 16 & $\mathrm{~F} / 36$ & $\mathrm{~L}$ & 8 & 6* & - & Otosclerosis \\
\hline
\end{tabular}

M: male; F: female; R: right ear; L: left ear. CSOM: chronic supppurative otitis media; NIHL: noise induced hearing loss; SSNHL: sudden sensory neural hearing loss. * Significant improvement in tinnitus. Mean score improvement is 0.62 . Mean of pre-treatment score is 6.81. Mean of post-treatment score is 6.12 .

Lidocaine was tested in the treatment of Meniere's disease by way of systemic administration [10] [11]. Following which, in the 1970s, Eiji Sakata administered lidocaine and dexamethasone intratympanically [10] [12]. However lignocaine had an unacceptable vertigo as its side-effect. 
Table 3. Gives the otologic diagnoses in the 14 ears of the control group (who received $0.5 \mathrm{ml}$ saline).

\begin{tabular}{|c|c|c|c|c|c|c|}
\hline \multirow[t]{2}{*}{ Patients No. } & \multirow[t]{2}{*}{ Sex/age } & \multirow[t]{2}{*}{ Side of symptom } & \multicolumn{2}{|c|}{ Visual analog scale score } & \multirow[t]{2}{*}{ Complications } & \multirow[t]{2}{*}{ Diagnosis } \\
\hline & & & Pre-treatment & Post-treatment & & \\
\hline 1 & $\mathrm{M} / 55$ & $\mathrm{~L}$ & 7 & $5^{*}$ & - & Presbyacusis \\
\hline 2 & $\mathrm{M} / 55$ & $\mathrm{R}$ & 7 & $5^{*}$ & - & Presbyacusis \\
\hline 3 & $\mathrm{~F} / 52$ & $\mathrm{R}$ & 6 & 6 & - & Presbyacusis \\
\hline 4 & $\mathrm{M} / 60$ & $\mathrm{R}$ & 7 & 7 & - & Presbyacusis \\
\hline 5 & $\mathrm{~F} / 32$ & $\mathrm{~L}$ & 5 & 5 & Vertigo & Idiopathic \\
\hline 6 & $\mathrm{~F} / 32$ & $\mathrm{R}$ & 5 & 5 & Vertigo & Idiopathic \\
\hline 7 & $\mathrm{M} / 27$ & $\mathrm{R}$ & 8 & $5^{*}$ & - & Idiopathic \\
\hline 8 & $\mathrm{~F} / 22$ & $\mathrm{~L}$ & 7 & 6 & - & Idiopathic \\
\hline 9 & $\mathrm{M} / 33$ & $\mathrm{R}$ & 7 & 7 & - & Idiopathic \\
\hline 10 & $\mathrm{M} / 47$ & $\mathrm{~L}$ & 6 & 6 & - & CSOM \\
\hline 11 & M/35 & $\mathrm{R}$ & 8 & $6^{*}$ & - & CSOM \\
\hline 12 & $\mathrm{M} / 40$ & $\mathrm{~L}$ & 7 & 6 & - & Menieres d. \\
\hline 13 & $\mathrm{M} / 40$ & $\mathrm{R}$ & 5 & 5 & Vertigo & Ototoxicity \\
\hline 14 & $\mathrm{M} / 34$ & $\mathrm{~L}$ & 6 & 5 & - & NIHL \\
\hline
\end{tabular}

M: male; F: female; R: right ear; L: left ear. CSOM: chronic supppurative otitis media; NIHL: noise induced hearing loss; ${ }^{*}$ Significant improvement in tinnitus. Mean score improvement is 0.83 . Mean of pre-treatment score is 6.58. Mean of post-treatment score is 5.75 .

Table 4. Sex.

\begin{tabular}{ccccc}
\hline Test & Value & df & p-value & Association is \\
\hline Pearson chi-square & 11.04 & 1 & 0.13 & Not significant \\
Fisher's exact test & 9.76 & & 0.16 & \\
\hline
\end{tabular}

Table 5. Age.

\begin{tabular}{|c|c|c|c|c|}
\hline Test & Value & df & p-value & Association is \\
\hline Pearson chi-square & 17.50 & 9 & 0.393 & \multirow[b]{2}{*}{ Not significant } \\
\hline Fisher's exact test & 16.67 & & 0.479 & \\
\hline
\end{tabular}

Table 6. Laterality.

\begin{tabular}{cccc}
\hline Test & Value & df & p-value \\
\hline Pearson chi-square & 8.09 & 1 & 0.573 \\
Fisher's exact test & 7.16 & 0.705 & Not significant \\
\hline
\end{tabular}

Table 7. Treatment.

\begin{tabular}{ccccc}
\hline Test & Value & df & p-value & 0.77 \\
Pearson chi-square & 32.86 & 6 & Association is & 0.44 \\
Fisher's exact test & 40.18 & & Not significant \\
\hline
\end{tabular}


There are different methods of IT injections. Tympanopunction i.e. Direct injection of the drug into the middle ear or myringotomy first followed by endoscopic examination of round window region followed by injection [13] [14]. In our study tympanopunction was done and a slow and steady injection was found to be a feasible mode of delivering the drug.

Actually, about $5 \mu \mathrm{l}$ is usually sufficient to fill the entire round window niche [15]. In IT therapy concentration of the drug and the duration for which it stays over the RWM is more important than the volume [16]. Injected volumes in published studies range from $<0.3 \mathrm{ml} \mathrm{[17]} \mathrm{to} 1 \mathrm{ml} \mathrm{[18]} \mathrm{[19]} \mathrm{at} \mathrm{the} \mathrm{higher} \mathrm{end.}$

Even in sudden deafness a high-rate of spontaneous recovery of hearing loss and accompanying tinnitus is a hallmark, which necessitates appropriate controls and there is still a lack of clear evidence of a therapeutic benefit of steroids with regard to tinnitus [20] [21].

In a placebo-controlled, double-blind crossover study in 20 patients with unilateral Meniere's disease, three consecutive daily i.t. injections of dexamethasone in a hyaluronate formulation showed no better effect on tinnitus than a placebo [22].

Simple placement of ventilation tube with no additional therapy has been reported in control of vertigo in many patients with menieres disease to a degree similar to endolymphatic sac surgery [23] [24]. Hence in our study, for patients with Meniere's disease grommet insertion was done and IT injections were given through the ventilation tube. These patients however didn't show significant improvement in tinnitus or other symptoms of the disease per se.

Other than steroids, i.v. administration of caroverine, has been tried [22] [25] but has failed. The compound has also been tried in form of local ear drops with claimed improvement of tinnitus [26].

AM-101, an NDMA receptor antagonist formulated in a hyaluronic acid gel, showed good tolerance and improvement in tinnitus status [17]. An open trial with IT administration of pilocarpine and carbachol showed a transient effect on the tinnitus [27].

RWM thickness (on average $70 \mu \mathrm{m}$ ) and, especially, its size varies widely in humans [2] and in some cases, its covered by an "false" membrane or by fibrous or fatty plugs within the niche itself [28]. False membranes are sometimes perforated or reticular [29]. Magnetic resonance imaging studies have shown no round window permeability in 5\% of ears, and poor permeability in $13 \%$ [30].

Also animal data has shown basal-apical concentration differences of over 1000-fold [16]. While direct determination of the gradient in a human cochlea is not feasible, it has been estimated in a computer-based simulation for IT gentamicin at around 100:1 (basal to apical levels) [31].

Since the sampling of inner ear fluids places hearing at risk [32]. Three studies with patients undergoing cochlear implantation, labyrinthectomy or translabyrinthine surgery found that perilymph concentrations varied significantly following IT injections of methylprednisolone [18], dexamethasone [33] or gentamicin [34].

Formulations or devices that ensure retention at RWM are preferable. This may be achieved by injecting viscous gel formulations, or by placing wicks, microcatheters [35] into, or close to, the round window niche. Gel-based formulations include hyaluronates [36], collagens [37], chitosans [38], fibrins [39], starch, celluloses, 6 elatin [40], poloxamers [41], and many others. Viscosity that is too high may also result in the formation of an air bubble on the RWM, thus preventing effective diffusion, or may temporarily impair the ossicular mobility.

It seems tempting, to enhance RWM diffusion of a drug by incorporating formulations that are known to enhance permeability, such as histamine or dimethylsulfoxide (DMSO) [42], prostaglandins or leukotrienes, or to use microsphere or nanoparticle formulations. However DMSO has been shown to be cytotoxic in cochlear organotypic cultures at concentrations between $0.5 \%$ and $6 \%$ [43] and may lead to reduced permeability [44].

Unlike dexamethasone, hydrocortisone has led to RWM inflammation after topical instillation [45]. In our study too, 4 cycles of IT dexamethasone injections didn't cause inflammation of the middle ear mucosa (Figure 3).

Local side effects, may include injection-site pain, dizziness, caloric vertigo, infection, persistent tympanic membrane perforation, or possible vasovagal or syncopal episodes during injection [14] [19] [46]. In our study no side-effects except for transient vertigo in few patients were noted. Sufficient warming of the drug, the use of fine needles [45] and appropriate local anaesthesia, a gentle rate of injection, and avoidance of excessive injection volumes seem to be key factors for good local tolerance.

\section{Conclusions}

Though IT therapy is a highly efficacious and tempting mode of drug delivery, IT dexamethasone injections are 


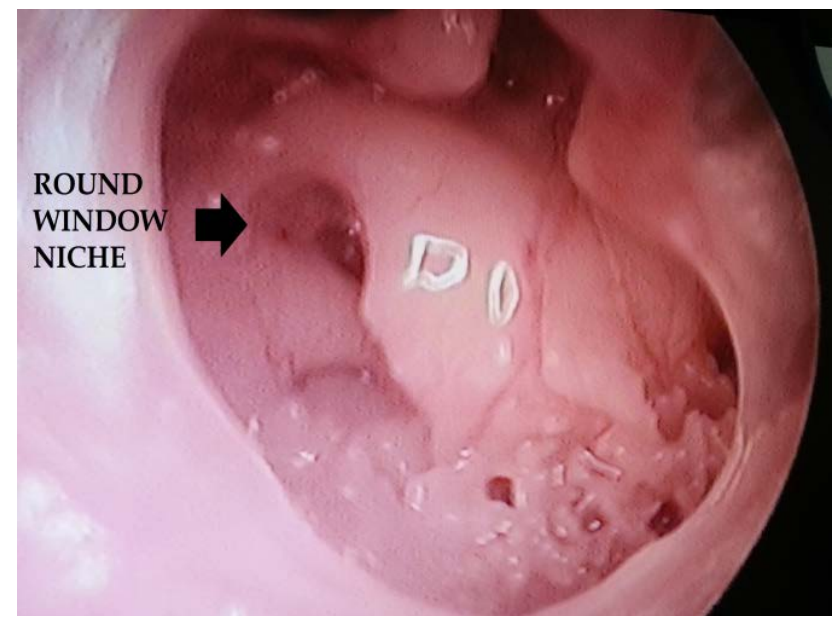

Figure 3. Normal mucosa after it dexamethasone injections.

not effective for refractory tinnitus and don't alter the hearing loss as per our study.

The lack of specific effective drugs must be considered the first and foremost obstacle for a more widespread use of the IT therapy.

The quest for the discovery of effective and safe therapeutic molecules should continue and hopefully there should be breakthrough in tinnitus therapy by intratympanic route in the near future.

\section{References}

[1] Goycoolea, M.V. and Lundman, L. (1997) Round Window Membrane. Structure Function and Permeability: A Review. Microscopy Research and Technique, 36, 201-211. http://dx.doi.org/10.1002/(SICI)1097-0029(19970201)36:3<201::AID-JEMT8>3.0.CO;2-R

[2] Goycoolea, M.V. (2001) Clinical Aspects of Round Window Membrane Permeability under Normal and Pathological Conditions. Acta Oto-Laryngologica, 121, 437-447. http://dx.doi.org/10.1080/000164801300366552

[3] Jahnke, K. (1980) The Blood-Perilymph Barrier. Archives of Otorhinolaryngology, 228, 29-34. http://dx.doi.org/10.1007/BF00455891

[4] Sakata, E., Itoh, A. and Itoh, Y. (1996) Treatment of Cochlear-Tinnitus with Dexamethasone Infusion into the Tympanic Cavity. International Tinnitus Journal, 2, 129-135.

[5] Shulman, A. and Goldstein, B. (2000) Intratympanic Drug Therapy with Steroids for Tinnitus Control: A Preliminary Report. International Tinnitus Journal, 6, 10-20.

[6] Cesarani, A., Capobianco, S., Soi, D., Giuliano, D.A. and Alpini, D. (2002) Intratympanic Dexamethasone Treatment for Control of Subjective Idiophatic Tinnitus: Our Clinical Experience. International Tinnitus Journal, 8, 11-113.

[7] Lustig, L.R. (2004) The History of Intratympanic Drug Therapy in Otology. Otolaryngologic Clinics of North America, 37, 1001-1017. http://dx.doi.org/10.1016/j.otc.2004.04.001

[8] Trowbridge, B.C. (1944) Injection of the Tympanum for Chronic Conductive Deafness and Associated Tinnitus Aurium: A Preliminary Report on the Use of Ethylmorphine Hydrochloride. Archives of Otolaryngology, 39, 523. http://dx.doi.org/10.1001/archotol.1944.00680010542012

[9] Trowbridge, B.C. (1949) Tympanosympathetic Anesthesia for Tinnitus Aurium and Secondary Otalgia. Archives of Otolaryngology, 50, 200-215. http://dx.doi.org/10.1001/archotol.1949.00700010209005

[10] Coles, R.R., Thompson, A.C. and O’Donoghue, G.M. (1992) Intra-Tympanic Injections in the Treatment of Tinnitus. Clinical Otolaryngology and Allied Sciences, 17, 240-242. http://dx.doi.org/10.1111/j.1365-2273.1992.tb01835.x

[11] Dodson, K.M. and Sismanis, A. (2004) Intratympanic Perfusion for the Treatment of Tinnitus. Otolaryngologic Clinics of North America, 37, 991-1000. http://dx.doi.org/10.1016/j.otc.2004.03.003

[12] Sakata, E. and Umeda, Y. (1976) Treatment of Tinnitus by Transtympanic Infusion of Lidocaine. Auris Nasus Larynx, 3, 133-138. http://dx.doi.org/10.1016/S0385-8146(76)80014-4

[13] Gouveris, H., Schuler-Schmidt, W., Mewes, T. and Mann, W. (2011) Intratympanic Dexamethasone/Hyaluronic Acid Mix as an Adjunct to Intravenous Steroid and Vasoactive Treatment in Patients with Severe Idiopathic Sudden Sensorineural Hearing Loss. Otology \& Neurotology, 32, 756-760. http://dx.doi.org/10.1097/MAO.0b013e31821a3fc3 
[14] Topak, M., Sahin-Yilmaz, A., Ozdoganoglu, T., Yilmaz, H.B., Ozbay, M. and Kulekci, M. (2009) Intratympanic Methylprednisolone Injections for Subjective Tinnitus. Journal of Laryngology \& Otology, 123, 1221-1225. http://dx.doi.org/10.1017/S0022215109990685

[15] Takahashi, H., Sando, I. and Takagi, A. (1989) Computer-Aided Three-Dimensional Reconstruction and Measurement of the Round Window Niche. Laryngoscope, 99, 505-509. http://dx.doi.org/10.1288/00005537-198905000-00008

[16] Salt, A.N. and Plontke, S.K. (2009) Principles of Local Drug Delivery to the Inner Ear. Audiology Neurotology, 14, 350-360. http://dx.doi.org/10.1159/000241892

[17] Muehlmeier, G., Biesinger, E. and Maier, H. (2011) Safety of Intratympanic Injection of AM-101 in Patients with Acute Inner Ear Tinnitus. Audiology Neurotology, 16, 388-397. http://dx.doi.org/10.1159/000322641

[18] Bird, P.A., Begg, E.J., Zhang, M., Keast, A.T., Murray, D.P. and Balkany, T.J. (2007) Intratympanic versus Intravenous Delivery of Methylprednisolone to Cochlear Perilymph. Otology \& Neurotology, 28, 1124-1130. http://dx.doi.org/10.1097/MAO.0b013e31815aee21

[19] Rauch, S.D., Halpin, C.F., Antonelli, P.J., Babu, S., Carey, J.P., Gantz, B.J., et al. (2011) Oral vs Intratympanic Corticosteroid Therapy for Idiopathic Sudden Sensorineural Hearing Loss: A Randomized Trial. Journal of the American Medical Association, 305, 2071-2079. http://dx.doi.org/10.1001/jama.2011.679

[20] Conlin, A.E. and Parnes, L.S. (2007) Treatment of Sudden Sensorineural Hearing Loss: I. A Systematic Review. Archives of Otolaryngology—Head \& Neck Surgery, 133, 573-581. http://dx.doi.org/10.1001/archotol.133.6.573

[21] Conlin, A.E. and Parnes, L.S. (2007) Treatment of Sudden Sensorineural Hearing Loss: II. A Meta-Analysis. Archives of Otolaryngology—Head \& Neck Surgery, 133, 582-586. http://dx.doi.org/10.1001/archotol.133.6.582

[22] Denk, D.M., Heinzl, H., Franz, P. and Ehrenberger, K. (1997) Caroverine in Tinnitus Treatment. A Placebo-Controlled Blind Study. Acta Oto-Laryngologica, 117, 825-830. http://dx.doi.org/10.3109/00016489709114208

[23] Montandon, P., Guillemin, P. and Hausler, R. (1988) Prevention of Vertigo in Ménière’s Syndrome by Means of Transtympanic Ventilation Tubes. ORL Journal of Oto-Rhino-Laryngology and Its Related Specialties, 50, 377-381. http://dx.doi.org/10.1159/000276016

[24] Sugawara, K., Kitamura, K., Ishida, T. and Sejima, T. (2003) Insertion of Tympanic Ventilation Tubes as a Treating Modality for Patients with Meniere’s Disease: A Short- and Long-Term Follow up Study in Seven Cases. Auris Nasus Larynx, 30, 25-28. http://dx.doi.org/10.1016/S0385-8146(02)00105-0

[25] Domeisen, H., Hotz, M.A. and Häusler, R. (1998) Caroverine in Tinnitus Treatment. Acta Oto-Laryngologica, 118, 606-608. http://dx.doi.org/10.1080/00016489850154801

[26] Ehrenberger, K. (2005) Topical Administration of Caroverine in Somatic Tinnitus Treatment: Proof-of-Concept Study. International Tinnitus Journal, 11, 34-37.

[27] DeLucchi, E. (2000) Transtympanic Pilocarpine in Tinnitus. International Tinnitus Journal, 6, 37-40.

[28] Alzamil, K.S. and Linthicum, Jr., F.H. (2000) Extraneous Round Window Membranes and Plugs: Possible Effect on Intratympanic Therapy. Annals of Otology, Rhinology \& Laryngology, 109, 30-32. http://dx.doi.org/10.1177/000348940010900105

[29] Nomura, Y. (1984) Round Window Niche and Round Window Membrane. In: Pfaltz, C.R., Ed., Otological Significance of the Round Window. Advances in Oto-Rhino-Laryngology, Vol. 33, S. Karger AG, Basel, 27-37.

[30] Yoshioka, M., Naganawa, S., Sone, M., Nakata, S., Teranishi, M. and Nakashima, T. (2009) Individual Differences in the Permeability of the Round Window: Evaluating the Movement of Intratympanic Gadolinium into the Inner Ear. Otology \& Neurotology, 30, 645-648. http://dx.doi.org/10.1097/MAO.0b013e31819bda66

[31] Plontke, S.K., Wood, A.W. and Salt, A.N. (2002) Analysis of Gentamicin Kinetics in Fluids of the Inner Ear with Round Window Administration. Otology \& Neurotology, 23, 967-974. http://dx.doi.org/10.1097/00129492-200211000-00026

[32] Banerjee, A. and Parnes, L.S. (2004) The Biology of Intratympanic Drug Administration and Pharmacodynamics of Round Window Drug Absorption. Otolaryngologic Clinics of North America, 37, 1035-1051. http://dx.doi.org/10.1016/j.otc.2004.04.003

[33] Bird, P.A., Murray, D.P., Zhang, M. and Begg, E.J. (2011) Intratympanic versus Intravenous Delivery of Dexamethasone and Dexamethasone Sodium Phosphate to Cochlear Perilymph. Otology \& Neurotology, 32, 933-936. http://dx.doi.org/10.1097/MAO.0b013e3182255933

[34] Becvarovski, Z., Bojrab, D.I., Michaelides, E.M., Kartush, J.M., Zappia, J.J. and LaRouere, M.J. (2002) Round Window Gentamicin Absorption: An in Vivo Human Model. Laryngoscope, 112, 1610-1613. http://dx.doi.org/10.1097/00005537-200209000-00015

[35] Borkholder, D.A. (2008) State-of-the-Art Mechanisms of Intracochlear Drug Delivery. Current Opinion in Otolaryngology \& Head \& Neck Surgery, 16, 472-477. http://dx.doi.org/10.1097/MOO.0b013e32830e20db 
[36] Borden, R.C., Saunders, J.E., Berryhill, W.E., Krempl, G.A., Thompson, D.M. and Queimado, L. (2011) Hyaluronic Acid Hydrogel Sustains the Delivery of Dexamethasone across the Round Window Membrane. Audiology Neurotology, 16, 1-11. http://dx.doi.org/10.1159/000313506

[37] Iwai, K., Nakagawa, T., Endo, T., Matsuoka, Y., Kita, T., Kim, T.S., et al. (2006) Cochlear Protection by Local Insulin-Like Growth Factor-1 Application Using Biodegradable Hydrogel. Laryngoscope, 116, 529-533. http://dx.doi.org/10.1097/01.mlg.0000200791.77819.eb

[38] Paulson, D.P., Abuzeid, W., Jiang, H., Oe, T., O’Malley, B.W. and Li, D. (2008) A Novel Controlled Local Drug Delivery System for Inner Ear Disease. Laryngoscope, 118, 706-711. http://dx.doi.org/10.1097/MLG.0b013e31815f8e41

[39] Sheppard, W.M., Wanamaker, H.H., Pack, A., Yamamoto, S. and Slepecky, N. (2004) Direct Round Window Application of Gentamicin with Varying Delivery Vehicles: A Comparison of Ototoxicity. Otolaryngology—Head and Neck Surgery, 131, 890-896. http://dx.doi.org/10.1016/j.otohns.2004.05.021

[40] Sakamoto, T., Nakagawa, T., Horie, R.T., Hiraumi, H., Yamamoto, N., Kikkawa, Y.S., et al. (2010) Inner Ear Drug Delivery System from the Clinical Point of View. Acta Oto-Laryngologica, 563, 101-104. http://dx.doi.org/10.3109/00016489.2010.486801

[41] Salt, A.N., Hartsock, J., Plontke, S., LeBel, C. and Piu, F. (2011) Distribution of Dexamethasone and Preservation of Inner Ear Function Following Intratympanic Delivery of a Gel-Based Formulation. Audiology Neurotology, 16, 323335. http://dx.doi.org/10.1159/000322504

[42] Chandrasekhar, S.S., Rubinstein, R.Y., Kwartler, J.A., Gatz, M., Connelly, P.E., Huang, E., et al. (2000) Dexamethasone Pharmacokinetics in the Inner Ear: Comparison of Route of Administration and Use of Facilitating Agents. Otolaryngology_Head and Neck Surgery, 122, 521-528.

[43] Mikulec, A.A., Hartsock, J.J. and Salt, A.N. (2008) Permeability of the Round Window Membrane Is Influenced by the Composition of Applied Drug Solutions and by Common Surgical Procedures. Otology \& Neurotology, 29, 1020-1026. http://dx.doi.org/10.1097/MAO.0b013e31818658ea

[44] Qi, W., Ding, D. and Salvi, R.J. (2008) Cytotoxic Effects of Dimethyl Sulphoxide (DMSO) on Cochlear Organotypic Cultures. Hearing Research, 236, 52-60. http://dx.doi.org/10.1016/j.heares.2007.12.002

[45] Belhassen, S. and Saliba, I. (2012) Pain Assessment of the Intratympanic Injections: A Prospective Comparative Study. European Archives of Oto-Rhino-Laryngology, 269, 2467-2473. http://dx.doi.org/10.1007/s00405-011-1897-z

[46] Stachler, R.J., Chandrasekhar, S.S., Archer, S.M., Rosenfeld, R.M., Schwartz, S.R., Barrs, D.M., et al. (2012) Clinical Practice Guideline: Sudden Hearing Loss. Otolaryngology—Head and Neck Surgery, 146, S1-S35. http://dx.doi.org/10.1177/0194599812436449 